\title{
UPAYA MENINGKATKAN KOMPETENSI GURU DALAM MENYUSUN SILABUS DAN RENCANA PELAKSANAAN PEMBELAJARAN MELALUI SUPERVISI AKADEMIK BERKELANJUTAN
}

\author{
Heri Bertus \\ Pemerintahan Provinsi Kalimantan Barat Dinas Pendidikan dan Kebudayaan \\ Email : heribertus_kelam@yahoo.co.id
}

\begin{abstract}
This study aims to prove scientifically whether ongoing academic supervision can improve teacher competencies in preparing Syllabus and Learning Implementation Plans, to find out the right steps in conducting academic supervision in order to be able to improve teacher competency in developing Syllabus and Learning Implementation Plans. The research method used is classroom action research. Data collection techniques in classroom action research are non-test techniques in the form of observation, questionnaires, and documentation. Research results include: (1) Continuous academic supervision is scientifically proven to improve teacher competence in preparing syllabus and lesson plans in Kelam Permai 1 Public High School. Ncreased teacher competence in developing a good syllabus from $31 \%$ to $83 \%$ after academic supervision. In addition, the number of good quality RPPs also increased from $31 \%$ to $89 \%$. (2) Syllabus and Learning Implementation Plans for Mathematics subject teachers are in accordance with the provisions stipulated in Permendikbud Number 21 of 2016 concerning Standard Content. The competence of teachers of Mathematics in preparing Syllabus and Learning Implementation Plans has increased since the ongoing implementation of academic supervision.
\end{abstract}

Keywords: Teacher Competence, Syllabus, Learning Implementation Plan, Academic Supervision 


\begin{abstract}
Abstrak
Penelitian ini bertujuan untuk membuktikan secara ilmiah apakah supervisi akademik berkelanjutan dapat meningkatkan kompetensi guru dalam menyusun Silabus dan Rencana Pelaksanaan Pembelajaran, untuk mengetahui langkah-langkah yang tepat dalam melakukan supervisi akademik agar mampu meningkatkan kompetensi guru dalam menyusun Silabus dan Rencana Pelaksanaan Pembelajaran. Metode penelitian yang digunakan adalah penelitian tindakan kelas. Teknik pengumpul data dalam penelitian tindakan kelas ini adalah teknik non tes berupa observasi, angket, dan dokumentasi. Hasil penelitian antara lain: (1) Supervisi akademik secara berkelanjutan terbukti secara ilmiah dapat meningkatkan kompetensi guru dalam menyusun Silabus dan RPP di SMA Negeri 1 Kelam Permai. Meningkatnya kompetensi guru dalam menyusun Silabus yang baik dari $31 \%$ menjadi $83 \%$ setelah supervisi akademik. Selain itu jumlah RPP yang berkualitas baik juga meningkat dari $31 \%$ menjadi 89\%. (2) Silabus dan Rencana Pelaksanaan Pembelajaran guru mata pelajaran Matematika sudah sesuai dengan ketentuan yang ditetapkan dalam Permendikbud Nomor 21 Tahun 2016 tentang Standar Isi. Kompetensi guru mata pelajaran Matematika dalam menyusun Silabus dan Rencana Pelaksanaan Pembelajaran sudah meningkat sejak dilaksanakannya supervisi akademik secara berkelanjutan.
\end{abstract}

Kata Kunci : Kompetensi Guru ,Silabus, Rencana Pelaksanaan Pembelajaran, Supervisi Akademik 


\section{A. Pendahulan}

Pendidikan merupakan wahana yang sangat strategis dalam meningkatkan kualitas sumber daya manusia yang merupakan faktor determinan pembangunan. Pendidikan adalah usaha sadar untuk menyiapkan peserta didik melalui kegiatan bimbingan, pengajaran, dan atau latihan bagi peranannya di masa yang akan datang (Undang-Undang Nomor 20 Tahun 2003 tentang Sistem Pendidikan Nasional). Dengan tidak bermaksud mengecilkan kontribusi komponen yang lainnya, komponen tenaga kependidikan atau guru merupakan salah satu faktor yang sangat esensi dalam menentukan kualitas peserta didiknya.

Guru merupakan salah satu unsur di bidang kependidikan yang harus berperan secara aktif dan menempatkan kedudukannya sebagai tenaga profesional sesuai dengan tuntutan masyarakat yang semakin berkembang. Dalam hal ini guru tidak semata-mata sebagai pengajar yang melakukan transfer ilmu pengetahuan, tetapi juga sebagai pendidik yang melakukan transfer nilai-nilai sekaligus sebagai pembimbing yang memberikan pengarahan dan menuntun siswa dalam belajar. Kelengkapan dari jumlah tenaga pengajar dan kualitas dari guru tersebut akan mempengaruhi keberhasilan siswa dalam belajar yang berujung pada peningkatan mutu pendidikan. Untuk itu guru dituntut profesional dalam menjalankan tugasnya, dan memiliki kinerja yang baik.

Undang-Undang Nomor 14 Tahun 2005 Bab IV pasal 20 (a) tentang guru dan dosen menyatakan bahwa standar prestasi kerja guru dalam melaksanakan tugas keprofesionalannya, guru berkewajiban merencanakan pembelajaran, melaksanakan proses pembelajaran yang bermutu serta menilai dan mengevaluasi hasil pembelajaran. Tugas pokok guru tersebut yang diwujudkan dalam kegiatan belajar mengajar merupakan bentuk kinerja guru Peningkatan kinerja guru akan berpengaruh pada peningkatan kualitas output sumber daya manusia yang dihasilkan dalam proses pendidikan dan pembelajaran. Kualitas pendidikan dan lulusan sering kali dipandang 
tergantung kepada peran guru dalam pengelolaan komponen-komponen pengajaran yang digunakan dalam proses belajar mengajar yang menjadi tanggung jawabnya. Untuk dapat mencapai hasil belajar yang optimal tentunya guru harus memiliki dan menampilkan kinerja yang maksimal selama proses belajar mengajar dengan menyesuaikan perkembangan ilmu pengetahuan dan teknologi.

Guru yang profesional perlu memiliki kemampuan untuk menggali informasi kependidikan dan bidang studi dari berbagai sumber, termasuk dari sumber elektronik dan pertemuan ilmiah, serta melakukan kajian atau penelitian untuk menunjang pembelajaran yang mendidik. Jika mengacu pada empat kompetensi yang harus dikuasai guru menurut kebijakan pemerintah, maka salah satu kompetensi yang spesifik dan terkait langsung dengan tugas guru adalah kompetensi profesional. Selain dengan meningkatkan kompetensi profesional guru, usaha untuk meningkatkan kinerja guru juga dapat melalui peningkatan motivasi kerja para guru. Guru mengajar karena ada sesuatu yang memotivasi dirinya untuk bekerja.
Motivasi kerja ini yang menyebabkan seorang guru bersemangat dalam menjalankan tugas sebagai pendidik karena telah terpenuhi kebutuhannya. Pemenuhan kebutuhan tersebut berkaitan dengan kepuasan kerja, dimana antara harapan guru terpenuhi oleh kenyataan yang diberikan organisasi.

Upaya meningkatkan kinerja guru juga dapat dilakukan dengan pemberian disiplin kerja yang memadai. Disiplin merupakan kesadaran dan kesediaan seseorang untuk mentaati semua peraturan organisasi dan norma- norma sosial yang berlaku. Disiplin pada hakikatnya merupakan kemampuan untuk mengendalikan diri dalam bentuk tidak melakukan suatu tindakan yang bertentangan dengan sesuatu yang telah ditetapkan. Untuk mencapai kompetensi guru yang maksimal, sekolah harus melaksanakan pembinaan terhadap guru baik melalui workshop, diskusi, dan supervisi edukatif. Hal ini harus dilakukan secara periodik agar kinerja dan wawasan guru bertambah dan berlangsung terus menerus sepanjang masa. Supervisi akademik sesungguhnya dapat 
dilaksanakan oleh Kepala Sekolah yang berperan sebagai supervisor, namun bila pihak sekolah membutuhkan bantuan dalam mensupervisi guru-gurunya karena keterbatasan waktu Kepala Sekolah atau kurang sinkronnya latar belakang pendidikan yang dimiliki oleh Kepala Sekolah dengan latar belakang pendidikan dari guru yang akan disupervisi, maka Kepala Sekolah dapat meminta bantuan Pengawas Akademik atau Pengawas Mata Pelajaran yang sesuai dengan mata pelajaran yang diajarkan oleh guru yang akan disupervisi, untuk melaksanakannya. Ini berarti bahwa Kepala Sekolah harus bekerjasama atau melakukan kolaborasi dengan Pengawas Mata Pelajaran dalam melaksanakan supervisi akademik di sekolah tersebut.

Dalam sistem organisasi pendidikan modern diperlukan supervisor khusus yang independen dan dapat meningkatkan objektivitas pembinaan dan pelaksanaan tugasnya. Jika supervisi dilaksanakan, maka supervisor harus mampu melakukan berbagai pengawasan dan pengendalian untuk meningkatkan kinerja guru.
Pengawasan dan pengendalian ini merupakan kontrol agar kegiatan pembelajaran di sekolah terarah pada tujuan yang telah ditetapkan. Pengawasan dan pengendalian juga merupakan tindakan preventif untuk mencegah agar guru tidak melakukan penyimpangan dan lebih cermat melaksanakan kegiatan pembelajaran. Pengawasan dan pengendalian yang dilakukan Kepala Sekolah atau Pengawas Mata Pelajaran terhadap guru, disebut supervisi Kegiatan Belajar Mengajar (KBM), yang bertujuan untuk meningkatkan kemampuan profesional guru dan meningkatkan kualitas pembelajaran melalui pembelajaran efektif.

\section{B. Metode}

Penelitian tindakan kelas adalah penelitian tindakan yang dilakukan dengan tujuan memperbaiki mutu praktik pembelajaran di kelas, yang berfokus pada pembelajaran di kelas dan mengenai hal-hal yang terjadi di kelas. Mulyasa (2009: 11) menjelaskan yang dimaksud dengan PTK adalah "suatu upaya untuk mencermati kegiataan belajar sekelompok peserta didik dengan memberikan sebuah 
tindakan (treatment) yang sengaja dimunculkan".

Lokasi Penelitian dilaksanakan di SMA Negeri 1 Kelam Permai Kabupaten Sintang Provinsi Kalimantan Barat, Jalan Raya Jetak Kecamatan Kelam Permai Kelurahan.

Subjek dalam penelitian ini adalah guru-guru mata pelajaran Matematika di SMA Negeri 1 Kelam Permai Kabupaten Sintang Provinsi Kalimantan Barat pada tahun pelajaran 2018/2019, yang terdiri dari 3 orang guru mata pelajaran Matematika.

Penelitian ini dilakukan dengan metode penelitian tindakan kelas yang berlangsung selama 2 siklus. Masing-masing siklus terdiri dari tahapan perencanaan, pelaksanaan, observasi dan refleksi. Prosedur penelitian yang dilakukan peneliti adalah dengan melaksanakan supervisi akademik yang meliputi supervisi tradisional dan supervisi klinis.

\section{Pembahasan dan Hasil}

1. Pembahasan

a. Pengertian Kompetensi

Kompetensi merupakan spesifikasi dari kemampuan, ketrampilan, dan sikap yang dimiliki seseorang serta penerapannya di dalam pekerjaan, sesuai dengan standar kinerja yang dibutuhkan di lapangan (Ditjen Dikdasmen, 2004: 4) Berdasarkan penjelasan tersebut seorang yang bekerja sebagai guru, yang menurut Undang-Undang Guru dan Dosen tahun 2006 merupakan pekerjaan profesional, guru harus memenuhi standar-standar minimal yang dibutuhkan oleh Depdiknas.

Majid (2005:6) menjelaskan kompetensi yang dimiliki oleh setiap guru akan menunjukkan kualitas guru dalam mengajar. Kompetensi tersebut akan terwujud dalam bentuk penguasaan pengetahuan dan profesional dalam menjalankan fungsinya sebagai guru. Diyakini Robotham (1996:27), kompetensi yang diperlukan oleh seseorang tersebut dapat diperoleh baik melalui pendidikan formal maupun pengalaman.

\section{b. Tugas Pokok dan Fungsi Kepala Sekolah \\ Dalam implementasi} Manajamen Berbasis Sekolah (MBS), Kepala Sekolah merupakan "the key person" keberhasilan peningkatan 
kualitas pendidikan di sekolah. Ia adalah orang yang diberi tanggung jawab untuk mengelola dan memberdayakan berbagai potensi masyarakat serta orang tua untuk mewujudkan visi, misi dan tujuan sekolah. Oleh karena itu dalam implementasi MBS kepala sekolah harus memiliki visi, misi, dan wawasan yang luas tentang sekolah yang efektif serta kemampuan profesional dalam mewujudkannya melalui perencanaan, kepemimpinan, manajerial, dan supervisi pendidikan. Ia juga dituntut untuk menjalin kerjasama yang harmonis dengan berbagai pihak yang terkait dengan program pendidikan.

$$
\text { Dalam implementasi MBS }
$$

kepala sekolah harus mampu berperan sebagai berikut, Tujuh kompetensi kepala sekolah di atas sering disingkat dengan EMASLIM:

1. Kepala sekolah sebagai Educator

2. Kepala Sekolah sebagai Manajer

3. Kepala Sekolah sebagai Administrator

4. Kepala Sekolah sebagai Supervisor

5. Kepala Sekolah sebagai Leader

6. Kepala Sekolah sebagai Innovator

7. Kepala Sekolah sebagai Motivator

\section{c. Pengertian Supervisi}

Konsep supervisi modern dirumuskan oleh Kimball Wiles (1967) sebagai berikut : "Supervision is assistance in the devolepment of a better teaching learning situation". Supervisi adalah bantuan dalam pengembangan situasi pembelajaran yang lebih baik. Rumusan ini mengisyaratkan bahwa layanan supervisi meliputi keseluruhan situasi belajar mengajar (goal, material, technique, method, teacher, student, an envirovment). Situasi belajar inilah yang seharusnya diperbaiki dan ditingkatkan melalui layanan kegiatan supervisi. Dengan demikian layanan supervisi tersebut mencakup seluruh aspek dari penyelenggaraan pendidikan dan pengajaran.

\section{Hasil}

Dari hasil wawancara dengan 3 (tiga) orang guru mata pelajaran Matematika di SMA Negeri 1 Kelam Permai, peneliti memperoleh informasi bahwa semua guru belum tahu kerangka penyusunan RPP Kurikulum 2013, hanya sekolah yang memiliki dokumen standar proses (satu buah), hanya satu orang guru yang pernah 
mengikuti pelatihan pengembangan RPP Kurikulum 2013, umumnya guru mengadopsi dan mengadaptasi RPP Kurikulum 2010, kebanyakan guru tidak tahu dan tidak paham menyusun RPP Kurikulum 2013 secara lengkap, mereka setuju bahwa guru harus menggunakan RPP Kurikulum 2013 dalam melaksanakan kegiatan pembelajaran yang dapat dijadikan acuan atau pedoman dalam proses pembelajaran.

\section{a. Kuantitas Silabus dan RPP tahun pelajaran 2018/2019}

Pada akhir tahun pelajaran 2018/2019, peneliti mencatat guru yang menyetorkan perangkat pembelajaran untuk ditandatangani. Hasil perhitungan perangkat pembelajaran yang dikumpulkan dapat dilihat pada tabel berikut:

Tabel 12

Daftar Setoran Perangkat Pembelajaran Tahun Pelajaran 2018/2019

\begin{tabular}{|c|l|c|c|c|}
\hline \multirow{2}{*}{ No } & \multicolumn{1}{|c|}{ Nama Guru Binaan } & \multicolumn{2}{|c|}{$\begin{array}{c}\text { Perangkat } \\
\text { Pembelajaran }\end{array}$} & \multirow{2}{*}{ Keterangan } \\
\cline { 3 - 4 } & & $\begin{array}{c}\text { Silabu } \\
\text { s }\end{array}$ & RPP & \\
\hline 1 & Devi Indrawati, S.Pd & Ada & Ada & Lengkap \\
\hline 2 & M. Nuraini, S.Pd & Ada & Ada & $\begin{array}{c}\text { Belum } \\
\text { Lengkap }\end{array}$ \\
\hline 3 & Natalia Indrayanti, S.Pd & Ada & Ada & $\begin{array}{c}\text { Belum } \\
\text { Lengkap }\end{array}$ \\
\hline
\end{tabular}

Sumber : Lembar kontrol setoran perangkat pembelajara 2018/2019

Lebih rinci dijelaskan, prosentase kelengkapan perangkat pembelajaran guru yang mengumpulkan perangkat pembelajaran sebelum kegiatan adalah

Tabel 12

Rekapitulasi Guru Yang Menyetorkan Perangkat Pembelajaran

\begin{tabular}{|c|l|c|c|c|}
\hline No & \multicolumn{1}{|c|}{ Komponen } & $\begin{array}{c}\text { Jumlah } \\
\text { seharusny } \\
\text { a }\end{array}$ & $\begin{array}{c}\text { Yang } \\
\text { mengumpulka } \\
\text { n }\end{array}$ & $\begin{array}{c}\text { \% Yang } \\
\text { mengumpulka } \\
\text { n }\end{array}$ \\
\hline 1 & Standar Isi Mapel & 3 & 3 & 100 \\
\hline 2 & Kalender Pendidikan & 3 & 3 & 100 \\
\hline 3 & Program tahunan & 3 & 3 & 100 \\
\hline 4 & Program semester & 3 & 3 & 100 \\
\hline
\end{tabular}




\begin{tabular}{|c|l|c|c|c|}
\hline 5 & KKM & 3 & 3 & 100 \\
\hline 6 & Analisis Tujuan Mapel & 3 & 2 & 66,67 \\
\hline 7 & Analisis Materi Mapel & 3 & 0 & 0 \\
\hline 8 & Analisis pemetaan SK/KD & 3 & 0 & 0 \\
\hline 9 & Silabus & 3 & 3 & 100 \\
\hline 10 & RPP & 3 & 3 & 100 \\
\hline 11 & Agenda Kegiatan Harian & 3 & 0 & 0 \\
\hline 12 & $\begin{array}{l}\text { Pelaksanaan Prog. } \\
\text { Semester }\end{array}$ & 3 & 3 & 100 \\
\hline 13 & Daftar hadir siswa & 3 & 3 & 100 \\
\hline 14 & Daftar nilai & 3 & 3 & 100 \\
\hline 15 & $\begin{array}{l}\text { Analisis Hasil Ulangan } \\
\text { harian }\end{array}$ & 3 & 0 & 0 \\
\hline 16 & Analisis hasil UTS & 3 & 0 & 0 \\
\hline 17 & Analisis butir soal & 3 & 0 & 0 \\
\hline 18 & Bank soal & 3 & 0 & 0 \\
\hline 19 & Program perbaikan dan & 3 & 0 & 0 \\
\hline 20 & Laporan hasil perbaikan & 3 & 0 & 0 \\
\hline \multicolumn{4}{|l|}{ Persentase Rata- } \\
\multicolumn{4}{|l|}{ rata } \\
\hline
\end{tabular}

Sumber : lembar kontrol pengumpulan silabus dan RPP Wakasek

Dari tabel di atas jelas terlihat bahwa data dasar guru yang meyusun perangkat pembelajaran dengan lengkap persentase rata-rata sebesar 53,33\%. Dari silabus dan RPP yang terkumpul ini, kemudian penulis melakukan penelaahan terhadap kualitas dari perangkat pembelajaran yang dikumpulkan.

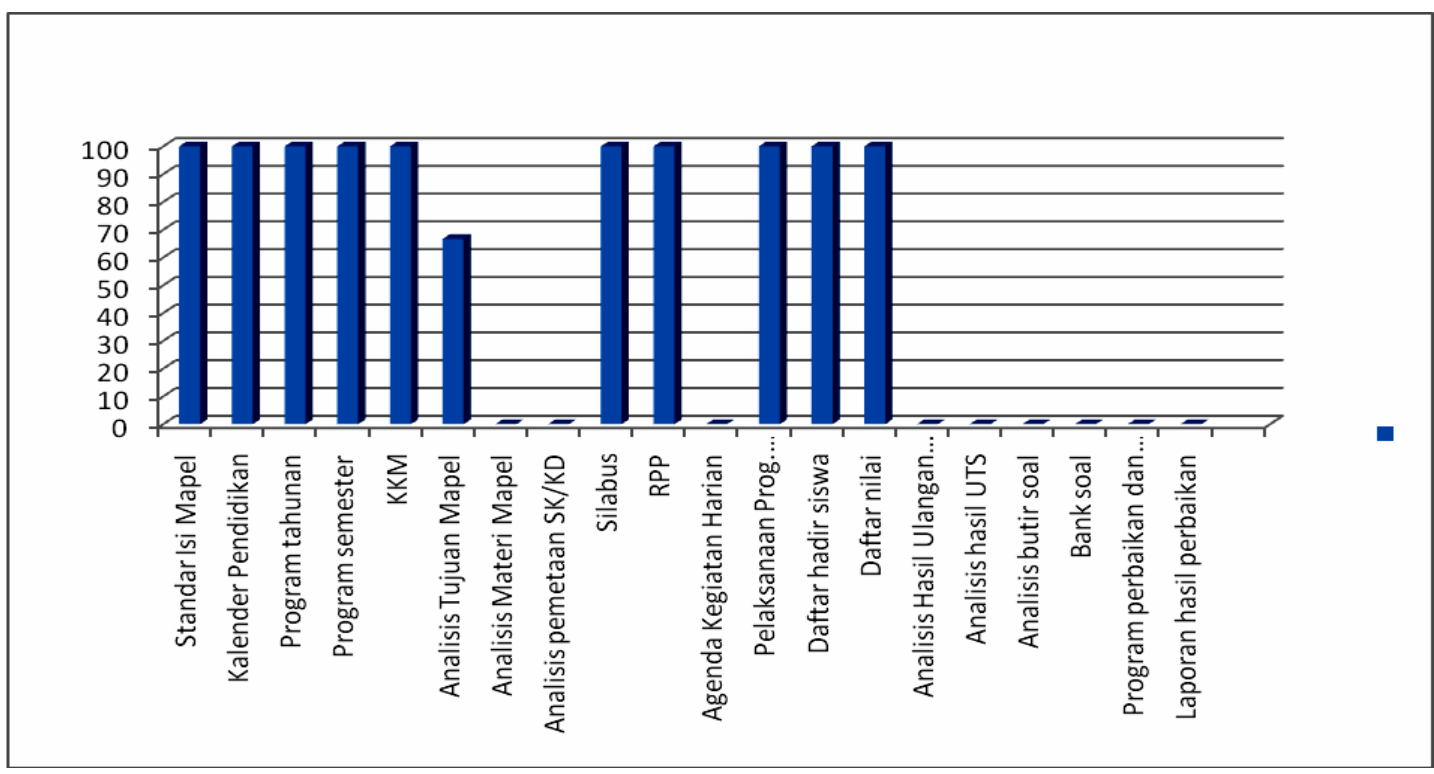


b. Kualitas

Perangkat pembelajaran Guru Tahun Pelajaran 2018/2019

Kualitas perangkat pembelajaran yang dibuat oleh guru SMA Negeri 1 Kelam Permai pada semester ganjil tahun pelajaran 2018/2019 secara umum dapat katakan kurang baik. Hal ini dikarenakan masih banyak perangkat pembelajaran khususnya Silabus dan RPP yang masih menggunakanormat lama dan terkesan tidak original (copy paste dari orang lain). Hal ini terlihat dari tidak timbulnya visi dan misi serta tujuan sekolah pada Silabus dan RPP yandibuat oleh guru.

\section{c. Kualitas Silabus dan RPP Yang Dibuat Guru Pada}

\section{Sikluske-1}

Pada awal bulan Agustus 2018, peneliti memerintahkan kepada seluruh guru mata pelajaran Matematika untuk membuat perangkat pembelajaran yang lengkap semua komponennya, dan dikumpulkan pada akhir bulan Agustus 2018. Pada minggu kedua bulan September 2018 peneliti mengumumkan akan melakukan supervisi terhadap guru-guru mata pelajaran Matematika yang akan dilaksanakan pada bulan Oktober. 2018. Pada siklus ini peneliti melakukan analisis dan penilaian terhadap kuantitas guru yang menyetorkan revisi perangkat pembelajaran terutama Silabus dan RPP.

\section{d. Kualitas Silabus dan RPP yang dibuat guru pada Siklus} ke-2

Dari data jumlah guru yang mengumpulkan silabus dan RPP pada awal siklus 1, dapat terlihat bahwa dengan informasi adanya Supervisi Akademik terhadap guru mata pelajaran Matematika dapat meningkatkan kualitas perangkat pembelajaran khususnya Silabus dan RPP yang sebelumnya hanya $66,50 \%$, mengalami peningkatan kualitas menjadi 79,50\%. Dari data tersebut juga dapat dilihat adanya guru yang hanya menyerahkan Silabus dan RPP tanpa adanya revisi yang signifikan dari komponen-komponen yang harus ada di perangkat pembelajaran tersebut.Sebelum melakukan supervisi individual terhadap seluruh guru mata pelajaran 
Matematika terutama kepada guru yang kualitas Silabus dan RPP masih di bawah $70 \%$.

\section{Simpulan}

1. Supervisi akademik secara berkelanjutan terbukti secara ilmiah dapat meningkatkan kompetensi guru dalam menyusun Silabus dan RPP di SMA Negeri 1 Kelam Permai. Ini terbukti dengan meningkatnya kompetensi guru dalam menyusun Silabus yang baik dari $31 \%$ menjadi $83 \%$ setelah supervisi akademik. Selain itu jumlah RPP yang berkualitas baik juga meningkat dari $31 \%$ menjadi $89 \%$.

2. Langkah-langkah yang mengakibatkan terjadinya peningkatan kompetensi guru dalam menyusun Silabus dan RPP tersebut meliputi langkah- langkah sebagai berikut: Pengumuman rencana supervisi terhadap guru. Pelaksanaan supervisi individual, dimana setiap guru diminta mempresentasikan silabus dan RPP-nya kepada Kepala sekolah berkolaborasi dengan Pengawas Mata Pelajaran, kemudian diberi masukan terhadap kekurangan silabus dan RPP guru mata pelajaran Matematika. Untuk mengecek originalitas Silabus dan RPP yang disusun guru, kepala sekolah berkolaborasi dengan Pengawas Mata Pelajaran melakukan supervisi kelas. Hal ini dilakukan untuk menyesuaikan rencana yang dimuat dalam Silabus dan RPP dengan penerapannya di kelas. Jika sesuai maka dapat 
dipastikan, bahwa Silabus dan

RPP guru mata pelajaran

Matematika di SMA Neger1

Kelam Permai sudah sesuai

dengan ketentuan yang

ditetapkan dalam Permendikbud

Nomor 21 Tahun 2016 tentang

Standar Isi. Kompetensi guru

dalam menyusun Silabus dan

RPP tersebut benar (bukan

jiplakan atau dibuatkan orang

lain). Kompetensi guru mata

pelajaran Matematika dalam

menyusun Silabus dan RPP

sudah meningkat sejak

dilaksanakannya supervisi

akademik.

\section{Daftar Pustaka}

Anwar, Moch. Idochi. 2004. Administrasi Pendidikan dan Manajemen

Biaya

Pendidikan. Bandung:

Alfabeta

Depdiknas. 2001. Manajemen Peningkatan Mutu Berbasis Sekolah. Jakarta: Depdiknas.
Depdiknas. 2014. Supervisi Akademik; Materi Pelatihan Penguatan Kemampuan Kepala

Sekolah; Jakarta: Depdiknas. Harahap, Baharuddin. 1983.

Supervisi Pendidikan yang Dilaksanakan oleh Guru, Kepala Sekolah, Penilik dan Pengawas Sekolah. Jakarta: Damai Jaya

Majid, Abdul. 2005. Perencanaan Pembelajaran:

Mengembangkan Standar Kompetensi Guru.

Bandung: PT Remaja Rosdakarya.

Sahertian, Piet A. 2000. Konsep-

Konsep dan Teknik

Supervisi Pendidikan

Dalam Rangka

Pengembangan Sumber

Daya Manusia. Jakarta: Rineka Cipta.

Sapari, Achmad. 2002. Pemahaman Guru Terhadap Inovasi Pendidikan. Artikel. Jakarta: Kompas (16 Agustus 2002).

Supandi. 1996. Administrasi dan Supervisi Pendidikan. Jakarta: Departemen Agama Universitas Terbuka.

Suprihatin, MD. 1989. Administrasi Pendidikan, Fungsi dan Tanggung Jawab Kepala Sekolah sebagai Administrator dan Supervisor Sekolah. Semarang: IKIP Semarang Press.

Suryasubrata. 1997. Proses Belajar Mengajar di Sekolah. Jakarta: Rineka Cipta.

Surya, Muhammad. 2003. Psikologi Pembelajaran dan 
Pengajaran. Bandung:

Yayasan Bhakti Winaya

Usman, Moh. Uzer. 1994. Menjadi

Guru Profesional.

Bandung: PT Remaja

Rosdakarya.

Wahidin; 13 Faktor untuk menjadi Kepala Sekolah Yang

Efektif, 2008

Wardani, IGK. 1996. Alat Penilaian

Kemampuan Guru (APKG).

Jakarta: Dirje 